\title{
Steady-State and Transient Modeling of Tracer and Nutrient Distributions in the Global Ocean
}

\author{
Progress Report \\ for Period June 1, 1991 - February 31, 1993
}

Thomas F. Stocker \& Wallace S. Broecker

Lamont-Doherty Geological Observatory of Columbia University

Palisades, New York, 10964

March 8, 1993

Prepared for

The U.S. Department of Energy

Agreement No. DE-FG02-91ER61202

1

MASTER 


\begin{abstract}
The balance of stable and decaying tracers was incorporated into a latitude-depth ocean circulation model which resolves the major ocean basin and is coupled to an atmospheric energy balance model. The modern distribution of radiocarbon and the analysis of artificial color tracers enabled the census of the deep water masses. We show that good agreement with the observation can be achieved if the surface forcing is modified. The same process could also account for longterm, large-scale changes of the global thermohaline circulation. Uptake rates of carbon are investigated using an inorganic carbon cycle model and performing $2 \times \mathrm{CO}_{2}$-experiments. We prescribe the industrial evolution of $\mathrm{pCO}_{2}$ in the atmosphere rom 1792 to 1988 and calculate the total flux of carbon into the world ocean. Results are in good agreement with two recent 3-dimensional model simulation. First results using an organic carbon cycle in this model are presented.

Changes in the hydrological cycle can stabilize the thermohaline circulation in the Atlantic and enable simulation of climate events resembling the Younger Dryas. By adding the balance of radiocarbon the evolution of its atmospheric concentration is studied during rapid changes of deep ocean ventilation. A resumption of ventilation creates a rapid decrease of atmospheric radiocarbon which is able to mask the natural decay.
\end{abstract}

\title{
1 Research Results
}

In this progress report we describe the research results that have been obtained under U.S. Department of Energy Agreement No. DE-FG02-91ER61202 from June 1, 1990 to February 31, 1992. This project will conclude on May 31, 1993. The present report forms part of a proposal for renewal.

\subsection{Water Mass Distribution in the World Ocean}

Incorporation of tracers into an ocean circulation model requires first that the model reproduces the principal water masses of the world ocean in a realistic way. The model we used is described in detail in Stocker et al. (1992a) and Wright \& Stocker (1992). It is a zonally averaged, latitudedepth ocean circulation model resolving the three major ocean basins and is coupled to an energy 
balance atmosphere. In order to check the location and concentration of water masses in this model we have added the balances of radiocarbon and artificial color tracers. While the former provide information on the time scales involved in cycling the water masses, the latter show the composition of the water masses according to their origin of formation. The results are reported in Stocker et al. (1992b; Appendix A). Only a brief summary is given here.

Forcing the model with the annually averaged surface values of temperature and salinity as given by Levitus (1982), North Atlantic Deep Water (NADW) is the dominant water mass throughout the deep ocean. We found that this surface forcing is not appropriate in the regions of deep water formation. Processes of deep water formation in ocean models are only crudely parameterized by convective removal of instabilities. By increasing the values of sea surface salinity to agree with those of the newly formed deep water in the high latitudes, a more realistic composition of the deep water masses is achieved. This result is consistent with recent findings in 3-dimensional ocean general circulation models (England, 1992).

The physical mechanism governing these adjustments is related to the north-south buoyancy contrast imposed at the surface. A sensitivity study was performed to understand the dependence of North Atlantic overturning and formation of Antarctic Bottom Water on the buoyancy contrast. We found that increasing the forcing in the Southern Ocean to surface values that are characteristic of those found presently in the North Atlantic, a global thermohaline circulation results that is in many ways consistent with that during the last glacial maximum $(18,000 \mathrm{BP})$. This suggests that large-scale reorganizations of the deep ocean circulation are closely linked to the north-south buoyancy contrast as well as to the existence of multiple equilibria.

\subsection{Transient Changes of the Thermohaline Circulation}

In the previous study (Stocker et al., 1992b) we also investigated transient changes between different circulation modes. The surface freshwater fluxes diagnosed from the modern and the "glacial" state are only slightly different but produce distinctly different deep circulations. A "glacial-interglacial transition" of the thermohaline circulation can be simulated by smoothly varying the surface fresh- 
water fluxes from one state to the other. This transition is modelled under mixed boundary conditions (with constant restoring surface temperatures and slowly varying surface freshwater fluxes); no rapid transitions are observed. This indicates that the world ocean can also undergo large-scale changes on a longer time scale even in the presence of multiple equilibria.

A subsequent investigation (Wright \& Stocker, 1993) concerned abrupt climatic events such as the Younger Dryas. For this purpose Dr. Daniel Wright developed a thermodynamic ice model which was put into the code during his visit at Lamont in November 1991 and another visit of one of us (TFS) at Bedford in June 1992. Surface boundary conditions were devised that allow a systematic study of the effect of river run-off and Arctic freshwater outflow on the stability of the deep ocean circulation. A decrease of the hydrological cycle from present-day levels by about $30 \%$ results in an ocean circulation that is sufficiently stable to exhibit transient behavior during a deglaciation experiment that is broadly consistent with the paleoclimatic record.

Using discharge rates of glacial meltwater (Fairbanks, 1989) into the North Atlantic, NADW formation collapses at the maximum of the first meltwater peak. Because heat is no longer delivered by the ocean to the area around the North Atlantic, sea and air surface temperatures drop, and a sea ice cover is formed. This cooling event, in many aspects consistent with the Younger Dryas, lasts for about 1200 years, at which time NADW formation spontaneously re-initiates, heat is again transported meridionally to the North Atlantic region, and the sea ice cover disappears. We have shown that it is possible to simulate transient changes of the thermohaline circulation with an ocean circulation model of lower order. The results are reported in Wright \& Stocker (199:; and enclosed in Appendix B.

\subsection{Transient Changes of Atmospheric Radiocarbon}

The experiments described above are repeated, and radiocarbon is included in the climate model assuming gas exchange between atmosphere and ocean on a time scale of 5 years. The results of this research are reported in a paper in preparation (Appendix C) and briefly summarized here.

The concentration of atmospheric radiocarbon, ${ }^{14} \mathrm{C}^{\text {atrn }}$, over the last 10,000 years has been found 
to vary on time scales from 100 to several 1000 years (Damon et al., 1978). These changes have long been attributed to a combination of the variability of the cosmogenic flux and the exchange between reservoirs. We have focussed on the variability of the oceanic uptake caused by changes of the thermohaline circulation. If ventilation of the deep ocean is suddenly interrupted, ${ }^{14} \mathrm{C}^{\text {atm }}$ increases because most of the oceanic reservoir can not be accessed any more. When ventilation resumes again, ${ }^{14} \mathrm{C}^{\mathrm{atm}}$ starts to decrease at a rate that is determined by the rapidity of the turn-on of deep ocean ventilation.

The evolution of ${ }^{14} \mathrm{C}^{\mathrm{atm}}$ is a measure of transient changes of the deep circulation of the world ocean, i.e. it reflects the global integral of the ocean's rate of ventilation. It has further implications for radiocarbon dating techniques which usually assume a constant atmospheric level. A rapid uptake creates an "age plateau". The radiocarbon age appears to remain constant for the time of rapid uptake, because the decrease in atmospheric concentration due to increased oceanic uptake masks the natural radioactive decay. Generally, the center of a plateau lags a climatic signal by about 400 years. We have compared the various simulations with the paleoclimatic record (Zbinden et al., 1989; Kromer \& Becker, 1993) and found indication that at least some of the plateaux nay have been due to rapid changes in the ocean circulation.

\subsection{Inorganic Carbon Cycle}

We have included an inorganic carbon cycle model following Maier-Reimer \& Hasselmann (1987) in this climate model. We study the uptake of carbon dioxide in $2 \times \mathrm{CO}_{2}$-experiments and during the industrial period. A sensitivity analysis is reported in Appendix D. We tested the influence of changes in the gas exchange rate, vertical diffusivity (with no change to the meridional overturning) and the mode of operation of the deep circulation on the airborne fraction. In the standard case our results are bracketed by those of the two commonly used 3-dimensional global ocean general circulation models. Oceanic r.ptake rates are also calculated for the period $1750 \mathrm{AD}$ to $1988 \mathrm{AD}$ when the evolution of the atmospheric $p \mathrm{CO}_{2}$ is prescribed. Additional uptake experiments follow the schedule agreed upon by the modeling groups of Princeton and MPI Hamburg. Uptake rates and excess carbon changes over the last few decades are determined and broken up latitudinally 
and in terms of temperature zones in the world ocean. Good agreement with the results of the Hamburg model is found (E. Maier-Reimer, pers. comm.). Currently, we also assess the model's capability ot simulate the uptake of bomb-produced radiocarbon.

\subsection{Organic Carbon Cycle}

The minimum building blocks of an organic carbon cycle in an ocean circulation model consist of 4 tracers: total carbon, alkalinity, phosphate and oxygen. In the ocean interior these tracers are mixed by advection, diffusion and convection, and carbon is exchanged with the atmosphere through gas exchange at the sea surface. To account for the biological pump transporting carbon from the surface layer to the deeper ocean we assume a prescribed, constant particulate flux which is exponentially decreasing with depth representing dissolution throughout the water column below the mixed layer. The formulation of interactions between these four species follows that of Bacastow \& Maier-Reimer (1990).

During spin-up all four tracers are relaxed to observed values at the surface in order to obtain steady state inventories. Productivity in the surface layer is calculated as a function of phosphate. For the further integration no surface exchange of phosphate and alkalinity is allowed; oxygen is still restored to saturation at the surface, and the flux of total carbon is proportional to the difference of $\mathrm{CO}_{2}$-partial pressures in the atmosphere and the ocean. In Fig. 1 preliminary steady-state distributions in Atlantic and Pacific are shown for total carbon, alkalinity, phosphate and oxygen. Total carbon and alkalinity are well represented in both Pacific and Atlantic; the maximum of phosphate as well as the lower concentrations of phosphate in NADW are well reproduced. However, anoxia in the Pacific and generally too low oxygen values in the intermediate Atlantic indicate that the formulation as well as the tuning of the organic carbon cycle component have to be re-examined. More important, the implementation of sediment chemistry is in progress and forms part of the proposal for renewal.

\section{DISCLAIMER}

This report was prepared as an account of work sponsored by an agency of the United States Government. Neither the United States Government nor any agency thireof, nor any of their employees, makes any warranty, express or implied, or assumes any legal liability or respons: bility for the accuracy, completeness, or usefulness of any information, apparatus, product, process disclosed, or represents that its use would not infringe privately owned trade name, trar.emark, ence herein to any specific commercial product, process, or service by trade name, tracemat, manufacturer, or otherwise does not necessarily constitute or imply its endorsement, recommendation, or favoring by the United States Government or any agency thereor. The views and opinions of authors expressed herein do not United States Government or any agency thereof. 


\section{Project-Related Research Activities}

\subsection{Mini Conference at Lamont-Doherty}

The variability of the formation of North Atlantic. Deep Water has implications for the global carbon cycle and is thus of relevance to the present project. With the financial support of the L-DGO Climate Center we organized a 2-day mini conference on NADW Formation as a Branch of the Hydrological Cycle held at Lamont on November 11 and 12, 1991. Leading experts on the subject covering aspects of modern observation, modelling and paleoclimate reconstruction were invited; a conference summary appeared in EOS (Stocker \& Broecker, 1992, Appendix E).

\subsection{Edition of JGR Special Volume}

The article in EOS received wide attention and one of the editors of the Journal of Geophysical Research encouraged us to edit a special issue on Observation and Modeling of North Atlantic Deep Water Formation and its Variability. About 24 papers were offered by participants and interested scientists; 10 are submitted currently.

\section{Future Studies}

These will he detailed in the accompanying proposal for renewal.

\section{References}

Archer D., and E. Maier-Reimer, Deep Sea $\mathrm{CaCO}_{3}$ burial and atmospheric $p \mathrm{CO}_{2}$, Nature, 1993, (subinitted).

Bacastow, R., and E. Maier-Reimer, Ocean-circulation model of the carbon cycle, Climate Dyn., $4,95-125,1990$. 
Damon, P.E., J.C. Lerman, and A. Long, Teporal fluctuations of atmospheric ${ }^{14} \mathrm{C}$ : causal factors and implications. Ann. Rev. Earth Planet. Sci., 6, 457-494, 1978.

England M.H., On the formation of Antarctic Intermediate and Bottom Water in ocean general circulation models. J. Phys. Oceanogr., 22, 918-926.

Fairbanks, R.G., A 17,000-year glacio-eustatic sea level record: influence of glacial melting rates on the Younger Dryas event and deep-ocean circulation. Nature, 342, 637-642, 1989.

Kromer, B., and B. Becker, German oak and pine ${ }^{14} \mathrm{C}$ calibration, $7200-9439 \mathrm{BC}$, Radiocarbon, 35 , $125-135,1993$.

Levitus, S., Climatological Atlas of the World Ocean. NOAA Prof. Paper, 13, 177 pp., 1982.

Maier-Reimer, E., and $\mathrm{K}$. Hasselmann, Transport and stroage of $\mathrm{CO}_{2}$ in the ocean - an inorganic ocean-circulation carbon cycle model, Climate Dyn., 2, 63-90, 1987.

Stocker, T.F., and W.S. Broecker, NADW formation as a branch of the hydrological cycle. EOS, Trans., Am. Geophys. Union, 73, 202-203, 1992.

Stocker, T.F., and D.G. Wright, Rapid transitions of the ocean's deep circulation induced by changes in surface water fluxes, Nature, 331, 729-732, 1991 a.

Stocker, T.F., D.G. Wright, and L.A. Mysak, A zonally averaged, coupled ocean-atmosphere model for paleoclimatic studies, J. Climate, 5, 773-797, 1992a.

Stocker, T.F., D.G. Wright, W.S. Broecker, The influence of high- latitude surface forcing on the global thermohaline circulation, Paleoceanography, 7, 529-541, 1992b.

Wright, D.G., and T.F. Stocker, Sensitivities of a zonally averaged global ocean circulation model, J. Geophys. Res., 97, 12707-12730, 1992.

Wright, D.G., and T.F. Stocker, Younger Dryas experiments. In: Ice in the Climate System, R.W. Peltier (ed.), NATO-ARW Proceedings, 1993, (in press).

Zbinden, H., M. Andree, H. Oeschger, B. Ammann, A. Lotter, G. Bonani, and W. Wölfli, At- 
mospheric radiocarbon at the end of the last glacial: an estimate based on AMS radiocarbon dates on terrestrial macrofossils from lake sediments. Radiocarbon, 31, 795-804, 1989.

\section{$5 \quad$ Figures}

Figure 1: Distribution of total carbon, alkalinity, phosphate and oxygen in the Atlantic (a) and Pacific (b) for a modern steady state circulation. There are still major discrepancies to the observed data in various areas which require further tuning of the organic part of the carbon . cycle model. 

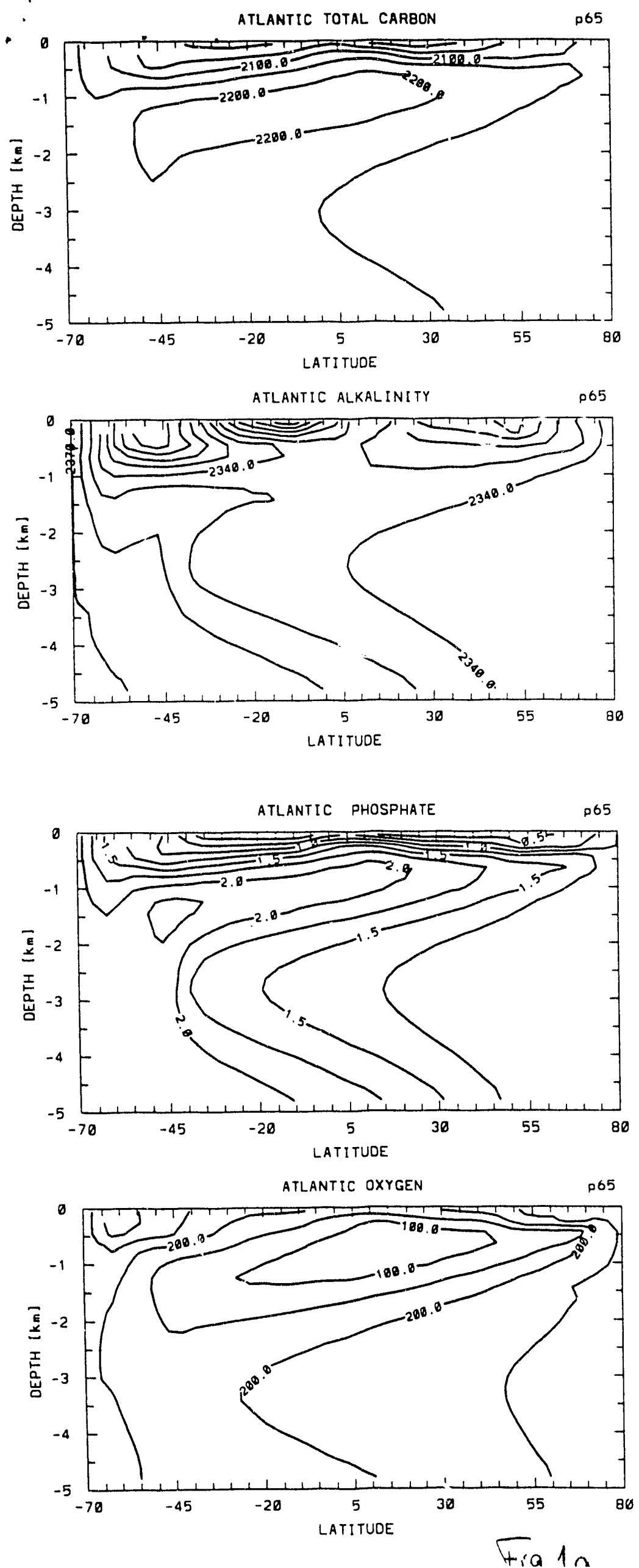
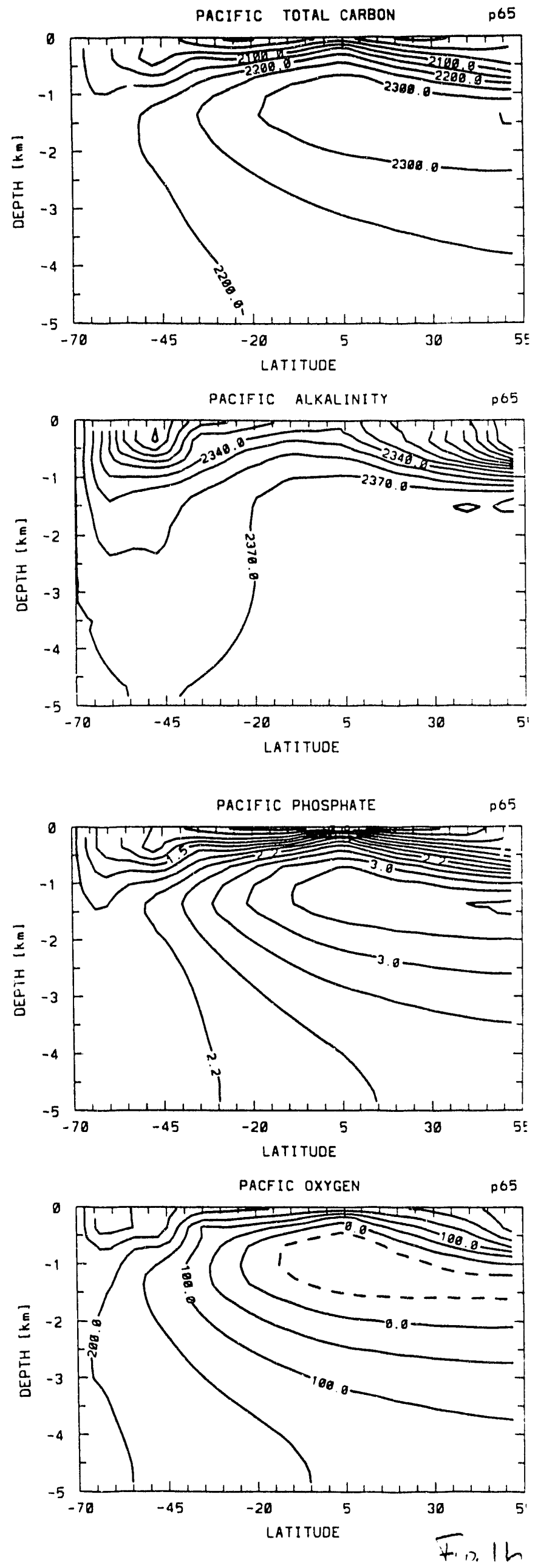

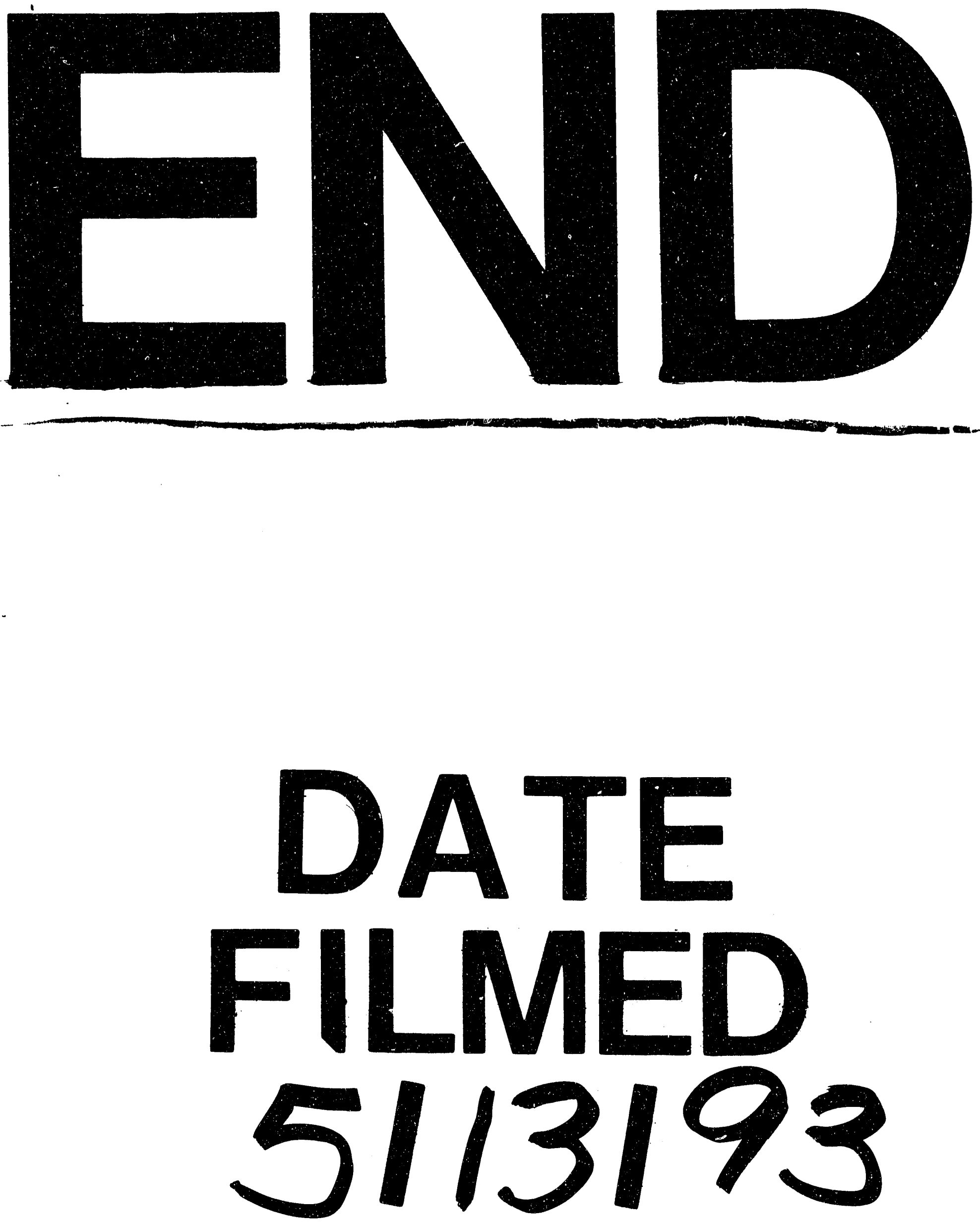

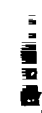


